\title{
Análise de segurança viária da rodovia BR-020 inserida no Distrito Federal
}

\author{
Road safety analysis of the BR-020 road inserted in the Distrito Federal \\ Análisis de seguridad vial de la carretera BR-020 insertada en el Distrito Federal
}

Recebido: 27/05/2021 | Revisado: 02/05/2021 | Aceito: 04/06/2021 | Publicado: 20/06/2021

\author{
Laís Costa Campos \\ ORCID: https://orcid.org/0000-0002-7501-527X \\ Universidade de Brasília, Brasil \\ laisccampos@gmail.com \\ Rafael Lopes Ferreira \\ ORCID: https://orcid.org/0000-0001-9496-4158 \\ Universidade de Brasília, Brasil \\ E-mail: rafael-munis@hotmail.com \\ Michelle Andrade \\ ORCID: https://orcid.org/0000-0002-7660-5853 \\ Universidade de Brasília, Brasil \\ E-mail: maccivil@gmail.com
}

\begin{abstract}
Resumo
O presente artigo tem como objetivo analisar o trecho da rodovia BR - 020, inserida no Distrito Federal, sob o aspecto de segurança viária. A fim de atingir esse objetivo realizou-se uma caracterização da rodovia, os tipos e as causas dos acidentes assim como seus georreferenciamentos a partir dos dados de acidentes fornecidos pelo Departamento da Polícia Rodoviária Federal (DPRF). Três métodos de identificação de locais concentradores de acidentes (metodologias do DNIT, do Ministério dos Transportes e de Meneses) foram aplicados à rodovia BR-020 para a localização dos trechos críticos nesta. A partir da comparação dos resultados obtidos por cada método, constataram-se deficiências nas metodologias adotadas, em que a metodologia proposta por Meneses foi considerada a mais completa dentre as três. E, através da identificação dos segmentos críticos comuns aos três métodos, realizou-se a análise de segurança ao detectar as deficiências presentes na via, assim como a proposição de melhorias a fim de aperfeiçoar a segurança viária, qualidade de vida e economia do Distrito Federal.
\end{abstract}

Palavras-chave: Rodovia; Segurança viária; Acidentes; Pontos críticos.

\begin{abstract}
This article focus on analysing the traffic safety at a BR-020 segment, located in Distrito Federal. To achieve this goal, the highway, accident types and causes were characterized. Using the accidents data provided by the Federal Highway Police Department, it was possible to georeference them. Three methods that identify critical segments were applied to the highway: DNIT methodology, Ministry of Transportation methodology and Meneses' methodology. After comparing the results from each methodology, flaws were found within each method, being the Meneses technique the most complete. Upon studying the critical highway segments, defective points were identified and improvements were suggested.
\end{abstract}

Keywords: Highway; Road safety; Accidents; Critical points.

\section{Resumen}

Este artículo tiene como objetivo analizar el tramo de la carretera BR-020, inserto en el Distrito Federal, bajo el aspecto de seguridad vial. Para lograr este objetivo, se realizó una caracterización de la carretera, los tipos y causas de accidentes, así como su georreferenciación a partir de los datos de accidentes proporcionados por la Policía Federal de Carreteras (DPRF). Se aplicaron a la carretera BR-020 tres métodos de identificación de sitios concentradores de accidentes (metodologías del DNIT, Ministerio de Transportes y Meneses) para la ubicación de tramos críticos en la misma. De la comparación de los resultados obtenidos por cada método, se encontraron deficiencias en las metodologías adoptadas, en las que la metodología propuesta por Meneses fue considerada la más completa entre las tres. Y, mediante la identificación de los tramos críticos comunes a los tres métodos, se realizó un análisis de seguridad para detectar las deficiencias presentes en la vía, así como la propuesta de mejoras con el fin de mejorar la seguridad vial, la calidad de vida y la economía. del Distrito Federal.

Palabras clave: Carretera; Carretera segura; Accidentes; Puntos críticos. 


\section{Introdução}

Os acidentes de trânsito tanto em ambientes urbanos quanto em ambientes rurais ocorrem devido a interrelação de quatro fatores - humano, veículo, via e ambiente (Oliveira, 2007).

Segundo um estudo da Organização Mundial da Saúde (OMS) (WHO, 2018), os acidentes de trânsito são a principal causa de mortes de jovens entre 5 e 29 anos e a oitava causa quando se analisa grupos de todas as idades, superando as taxas de morte por HIV/AIDS e tuberculose.

De acordo com WHO (2015), há consideráveis evidências de que intervenções são eficazes em melhorar a segurança das rodovias, já que os acidentes de trânsito são em sua maioria previsíveis.

Essas intervenções muitas vezes são resultados dos estudos dos locais e trechos críticos de um sistema viário, os quais possibilitam além de se fazerem as correções desses locais, obterem-se indicações para a melhoria da rede. Assim, a análise dos pontos críticos é uma forma de se estabelecer políticas de melhoramento dos níveis de segurança e uma referência para a reestruturação e atualização das especificações e normas de projetos de segurança e engenharia rodoviária (BRASIL, 2009).

Pode-se verificar, por exemplo, que, apesar do aumento do número absoluto de acidentes de trânsito, a taxa de mortes mundial permaneceu praticamente constante em 18 mortes por 100 mil habitantes nos últimos 15 anos. Isso se deve, principalmente, a melhorias nas vias, leis mais eficazes e campanhas informativas, pois mesmo com o aumento da frota de veículos e população, a taxa relativa de óbitos continuou inalterada (WHO, 2018).

\subsection{Definição do problema}

Apesar do esforço do governo federal em melhorar a segurança rodoviária, através do programa PARE e de projetos e campanhas educativas, por exemplo, ainda assim os acidentes de trânsito constituem um grave problema nacional. Além do impacto psicológico devido à perda de vidas humanas e sequelas provocadas nas vítimas, é inevitável a existência de custos econômico-financeiros que impactam as famílias, o estado e consequentemente a sociedade em geral.

Dentre os países mais populosos do mundo, o Brasil é aquele que mais aplica leis de controle de risco, como a lei seca e a obrigatoriedade no uso de equipamentos de segurança (cinto de segurança e capacete). Por exemplo, Andreucci et. al (2011) mostram que, devido a lei seca, para o Estado de São Paulo houve uma queda de 7,2 dos acidentes fatais no período de 2001 até 2010, e se for considerado apenas a capital paulista, esse número passa a apresentar uma queda de 16\%. Entretanto, o Brasil continua sendo o país com o maior número de mortes de trânsito por habitante da América do Sul. E, no globo terrestre, ocupa a $3^{\mathrm{a}}$ posição mundial em mortes por acidentes de trânsito (38.651 mortes), superado apenas pela Índia e China que possuem 150.785 e 58.022 mortes, respectivamente. (WHO, 2018).

Entre o período de 2007 a 2018, o Instituto de Pesquisa Econômica Aplicada (IPEA) calculou em 1,584 trilhão o custo com acidentes no país. Considerando que, neste período, os acidentes rodoviários foram responsáveis por aproximadamente 1,568 trilhão de reais, é notável que a redução desses represente uma grande probabilidade de ganho social.

Apenas no ano de 2015 mais de 120.000 acidentes foram computados pela Polícia Rodoviária Federal nas rodovias nacionais. Diante desse elevado número, a segurança tem sido bastante explorada pelos sistemas de transporte e sua infraestrutura (PRF, 2016).

Schawab (2019), classificou a malha rodoviário brasileira como uma nota $3 \mathrm{em}$ uma escala que varia de 1 (pior) a 7 (melhor), o que faz com que o Brasil ocupe a $116^{\mathrm{a}}$ posição de 141 países analisados. Segundo o CNT (2021), a crise fiscal enfrentada com pelo Brasil nos últimos anos somada aos gastos com saúde relacionados ao COVID-19, fizeram os investimentos em manutenção, adequação, interligação e ampliação da infraestrutura de transportes do país diminuírem.

Diante do que foi exposto, vê-se a necessidade de aprofundar o estudo de segurança no tráfego em rodovias com uma análise que relacione as características físicas e operacionais à segurança das vias. 
A partir dessa questão, foi realizada uma revisão de métodos de identificação de locais críticos de acidentes e da caracterização destes que, juntamente com os dados de acidentes da PRF (2016), viabilizem a identificação de trechos críticos em rodovias.

\subsection{Objetivos}

Objetiva-se com este artigo identificar os pontos críticos da rodovia BR-020, realizar uma comparação dos métodos utilizados para tal fim a partir dos seus resultados e, assim, analisar a rodovia sobre o aspecto de segurança.

\subsection{Metodologia de pesquisa}

Inicialmente, a partir da revisão bibliográfica foram analisados diferentes métodos de identificação de segmentos críticos, os quais foram aplicados na rodovia em análise. A partir dos resultados obtidos por cada método, foi feito o georreferenciamento dos pontos críticos na extensão da Rodovia BR-020, seguida da tipificação dos acidentes ocorridos nesses trechos. Em visita local, foram feitas observações para subsidiar a identificação das causas dos acidentes naquelas regiões bem como auxiliar na identificação de melhorias no que tange a segurança viária. Finalmente foi feita uma comparação das metodologias aplicadas à BR-020.

\subsection{Justificativa}

Há anos o modal rodoviário tem sido a preferência na movimentação de pessoas e bens no Brasil: apenas na matriz de transportes de cargas, possui uma participação de (61\%). Já na matriz de transporte de passageiros esse número chega a 95\% de participação. Ademais, é o principal responsável pela integração de todo o sistema de transporte e contribui significativamente para o desenvolvimento socioeconômico do país, segundo a Confederação Nacional do Transporte (CNT, 2015).

Conforme o Relatório da CNT (2019), o estado geral, pavimento, sinalização e geometria da via são características que influenciam de forma direta nas causas dos acidentes. Nesta pesquisa rodoviária, a CNT classifica as rodovias em ótimo, bom, regular, ruim e péssimo. O Distrito Federal possui $473 \mathrm{~km}$ de rodovia, sendo $5 \mathrm{~km}$ em péssimo estado, $30 \mathrm{~km}$ em estado ruim, $177 \mathrm{~km}$ em estado regular, $158 \mathrm{~km}$ em bom estado e $103 \mathrm{~km}$ em péssimo estado. E, Apesar da BR - 020 ter uma classificação de regular a boa, ainda assim, são verificados um grande número de acidentes em suas extensões. Segundo os dados da Polícia Rodoviária Federal, no ano de 2016, houve 1.066 acidentes nas rodovias fiscalizadas, nas quais 58 pessoas morreram. Dos acidentes registrados, 386 ocorreram na BR-020, com 16 vítimas fatais, concentrando o maior número de mortes das rodovias do Distrito Federal (DF) (PRF, 2016).

Dessa forma, verifica-se a necessidade de identificar os trechos concentradores de acidentes da Rodovia BR-020, com o intuito de buscar direcionamento para melhorar a segurança.

\section{Metodologias para Identificação e Tratamento de Locais Concentradores de Acidentes}

Segundo Luz (1994), existem três classificações de acidentes: acidente com danos materiais, com danos pessoais e misto, o qual resulta em danos materiais e pessoais simultaneamente. Acidentes com danos materiais são aqueles que causam apenas perdas materiais nos veículos envolvidos ou no ambiente urbano. Os acidentes com perdas pessoais são aqueles que resultam em vítimas com algum tipo de lesão e vítimas fatais. Já os acidentes mistos, ocorrem no mesmo acidente os dois tipos de perda.

Há uma outra classificação em que os acidentes podem ser diferenciados em acidentes sem vítimas, que se só resultem em perdas materiais; acidentes com vítimas, nos quais sucedem em uma ou mais vítimas com algum tipo de lesão; e por 
último, acidentes que decorrem em vítimas fatais no local do acidente, de acordo com Henrique (2002). Todos os métodos utilizados nesse estudo usam a definição de acidentes de Luz (1994) ou Henrique (2002), ou adaptação de um destes, para poder classificar os pontos críticos de rodovias.

Os métodos utilizados neste artigo para identificação de trechos críticos se dividem em estatísticos: DNIT (BRASIL, 2009) e Meneses (2001), e numérico: PARE-MT (BRASIL, 2002). O método de DNIT foi escolhido por ser a ferramenta atualmente utilizada na identificação dos trechos críticos nas rodovias federais. Escolheu-se o do PARE-MT por ser um método numérico, diferentemente do DNIT e Meneses, e por considerar o grau de severidade dos acidentes em sua análise. Por fim, o método de Meneses foi aplicado por ser um método que une tanto características do método do DNIT quanto da metodologia PARE-MT.

Os métodos numéricos são os de mais fácil aplicação e identificam os locais críticos a partir do cálculo de indicadores (quantidade de acidentes, taxa de acidentes), comparados com um valor previamente estabelecido. O local crítico será aquele em que o valor calculado é maior que o valor de referência.

Na metodologia do PARE-MT são utilizadas as técnicas: i) número de acidentes, ii) severidade dos acidentes, iii) taxa de acidentes e iv) taxa de severidade na identificação de pontos críticos. As técnicas do número de acidentes e da severidade não utilizam o volume de tráfego em seus cálculos, diferentemente das taxas. A abordagem da severidade dos acidentes é feita pelas técnicas de severidade e taxa de severidade, em que associam um determinado peso a cada acidente de acordo com sua severidade. Dessa forma, a quantidade de acidentes é expressa em Unidade Padrão de Severidade (UPS). Os pesos atribuídos aos acidentes são observados na Tabela 1 .

Tabela 1: Pesos Relacionados à Severidade.

\begin{tabular}{l|c}
\hline Classificação dos acidentes & Pesos \\
\hline Acidentes somente com danos materiais & 1 \\
\hline Acidentes com feridos & 4 \\
\hline Acidentes com feridos envolvendo pedestres & 6 \\
\hline Acidente com vítima(s) fatal(is) & 13 \\
\hline
\end{tabular}

Fonte: Autores.

Observa-se então que, no cálculo das taxas de severidade, além de se considerar a severidade dos acidentes, a neutralização da influência do volume de veículos também é abordada. Devem-se excluir os locais/trechos com número de acidentes menor ou igual a três, exceto aqueles com registro de pelo menos um óbito no período de estudo na aplicação deste método.

Já os métodos estatísticos envolvem a utilização de modelos matemáticos probabilísticos que determinam os locais onde o risco de acidentes é superior ao estimado ou esperados. Na definição do segmento crítico, é apresentada uma regra de decisão formulada através de um teste de hipótese, o qual requer um nível de significância.

A metodologia do DNIT (2009), parte inicialmente da descrição dos trechos do PNV (Plano Nacional de Viação) com seus respectivos marcos quilométricos, aos quais são associados os números de acidentes ocorridos. Após a separação dos acidentes nos respectivos trechos do PNV, os segmentos são separados em subtrechos em que é feita a análise dos índices de acidentes e a definição dos segmentos críticos. O trecho é considerado crítico caso o índice de acidentes (Ij) seja superior ao índice crítico (Ic). Por fim, é necessário estruturar uma série histórica regressiva de três anos de cada segmento a partir do anobase. Isto é feito para verificar a variação do índice de acidentes e a constância do segmento definido como crítico em função do tempo para diferentes níveis de significância. É realizada, então, uma listagem completa dos segmentos críticos. 
A metodologia proposta por Meneses (2001) também considera a severidade dos acidentes, assim como utiliza um método estatístico muito similar ao do DNIT para a identificação do local crítico.

A determinação dos segmentos críticos é baseada na análise de três índices: (i) o índice de acidente, (ii) índice médio de acidentes e (iii) índice crítico de acidentes. Estes índices são calculados a partir da determinação do Número Equivalente de Acidentes (NEAs), o qual leva em consideração a análise dos acidentes fatais com ou sem pedestres, acidentes com vítimas e sem vítimas utilizando também uma ponderação baseada em estudos econômicos de acidentes de trânsito registrados em vias urbanas. Após a definição dos índices de cada segmento verifica-se se o índice de acidentes é superior ao índice crítico de acidentes. Em caso afirmativo, o trecho é considerado crítico. Em caso negativo, se o trecho apresentar um índice médio de acidentes elevado, uma análise subjetiva é feita para saber se o trecho deve ser descartado ou estudado de modo específico.

Ante o exposto, esses três métodos configuram-se como metodologia quantitativa, já que a partir de fórmulas determinadas obtiveram-se os pontos críticos. No entanto, a análise dos pontos críticos, assim como a comparação realizada entre os métodos se enquadram na metodologia qualitativa. Portanto, de acordo com Pereira et al (2018), utilizou-se a metodologia quali-quantitativa, em que ambas as metodologias se complementam, para obtenção dos resultados.

A Figura 1 traz o fluxograma dos passos utilizados por cada método para obtenção dos locais críticos.

Figura 1: Fluxograma das Etapas dos Métodos Utilizados.

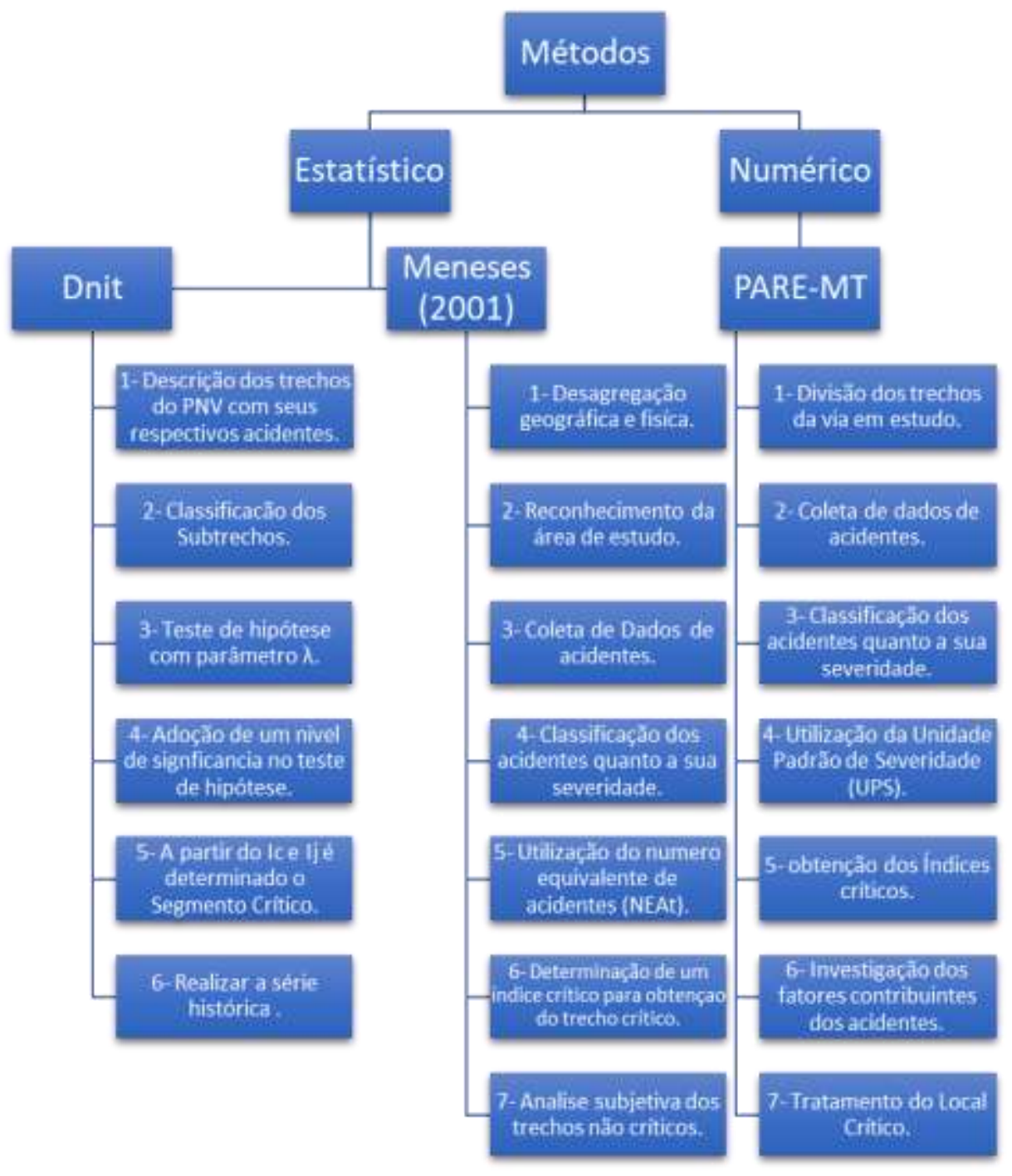

Fonte: Autores. 


\section{Identificação de Trechos Críticos na BR-020/DF}

\subsection{Caracterização da BR-020}

A rodovia BR-020 é uma rodovia federal radial com uma extensão total de $2.038,5 \mathrm{~km}$. Seu ponto inicial localiza-se na cidade de Brasília no Distrito Federal, e o final, em Fortaleza, no estado do Ceará. O segmento da rodovia inserida no Distrito Federal atravessa regiões administrativas econômicas fundamentais, como Sobradinho e Planaltina, além de ligar centros populacionais importantes com a capital.

Quanto à situação física e ao uso/ocupação do solo, o segmento da rodovia da BR - 020 dentro do Distrito Federal apresenta toda extensão pavimentada, que se inicia no km 0 até a divisa com Goiás, na cidade de Formosa, no km 57,1. Esse trecho da BR -020 é duplicado, tendo ainda alguns locais com três faixas, passando por trechos urbanos e rurais. Em algumas partes de sua extensão, vias marginais são utilizadas como uma forma de reduzir conflitos entre veículos de passagem e os locais, além de adotar alguns procedimentos como a faixa reversa, em horários específicos, para fornecer maior fluidez ao trânsito. A rodovia possui um canteiro central com distância adequada (padrão) e em alguns trechos interseções em desnível os quais minimizam as possibilidades de conflitos veiculares

Segundo os dados da Polícia Rodoviária Federal, no ano de 2014, houve 1.315 acidentes nas rodovias fiscalizadas do Distrito Federal, na qual 46 pessoas morreram. Dos acidentes registrados, cerca de $41 \%$ ocorreram na BR-020, e dos acidentes fatais, $21 \%$ ocorreram nessa mesma rodovia. No ano de 2015 foram registrados 245 acidentes na BR-020 no sentido BrasíliaFormosa. Desses, 85 foram acidentes sem vítimas, 146 acidentes com vítimas, 8 atropelamentos e 6 com vítimas fatais.

\subsection{Coleta de dados}

A coleta de dados dos acidentes para esse estudo foi feita através das informações disponibilizadas pela Policia Rodoviária Federal (PRF, 2016) em seu sítio na internet. A partir dos boletins de ocorrência, a PRF contabilizou e organizou trimestralmente, a cada ano, as informações de acidentes. Os dados utilizados na composição da tabela são: data, estado, cidade, rodovia, quilômetro do acidente, sentido da rodovia, tipo de acidente, classificação quanto à severidade e o número de acidentados.

A coleta de dados do volume de tráfego diário (VMD) foi realizada por meio de contato com o DNIT, em que foram obtidos os dados de volume médio anual de tráfego (VMDA) do ano de 2015 registrados pelos equipamentos eletrônicos de fiscalização presentes na rodovia BR-020, inserida no Distrito Federal.

Com esse banco de informações disponibilizado e com a utilização do programa de edição de planilhas Excel, manipularam-se os dados de forma a obter aqueles referentes aos acidentes ocorridos no trecho da BR-020 situado no Distrito Federal. Foi realizada também a separação dos trechos segundo o Plano Nacional de Viação (PNV) (BRASIL, 2010), associando a cada trecho a quantidade de acidentes e as suas respectivas severidades (sem vítima, com vítima, atropelamento e com vítima fatal).

\section{Aplicação dos Métodos de Identificação de Trechos Críticos}

$\mathrm{Na}$ aplicação dos três métodos a rodovia inserida no Distrito Federal foi dividida em trechos de acordo com o Plano Nacional de Viação (BRASIL, 2010), a qual é pista dupla em toda sua extensão. Esses trechos foram subdivididos em subtrechos com extensão variando de 1 a 1,9 quilômetros.

\subsection{Método DNIT}

Para utilização deste método (BRASIL, 2009), o número absoluto de acidentes e o volume médio diário de tráfego foram associados aos respectivos subtrechos. Foi utilizado um nível de significância de 5\%, em que a certeza de que os segmentos são identificados como crítico é igual ou inferior a 95\%. 
Os resultados de parte dos subtrechos classificados como críticos encontram-se na Tabela 2.

Tabela 2: Segmentos críticos definidos a partir do Método do DNIT para o ano de 2015.

\begin{tabular}{|c|c|c|c|c|c|c|c|c|c|}
\hline $\begin{array}{l}\text { PNV } \\
(\mathrm{km})\end{array}$ & $\begin{array}{l}\text { Se } \\
\text { gmentos } \\
(\mathrm{km})\end{array}$ & Acidentes & VMD & $\begin{array}{c}\text { Extensão } \\
\qquad(\mathrm{km})\end{array}$ & $\mathrm{k}$ & $\lambda$ & IC & $\mathrm{Ij}$ & Criticidade \\
\hline \multirow{2}{*}{$0-2,5$} & $0-1,5$ & 1 & 29.142 & 1,5 & 1,645 & 0,125 & 0,240 & 0,063 & Não \\
\hline & $1,5-2,5$ & 2 & 29.142 & 1 & 1,645 & 0,125 & 0,257 & 0,188 & Não \\
\hline \multirow{3}{*}{$2,5-6,0$} & $2,5-3,5$ & 5 & 29.142 & 1 & 1,645 & 0,954 & 1,399 & 0,470 & Não \\
\hline & $3,5-4,5$ & 11 & 19.484 & 1 & 1,645 & 0,954 & 1,486 & 1,547 & Crítico \\
\hline & $4,5-6,0$ & 9 & 19.484 & 1,5 & 1,645 & 0,954 & 1,398 & 0,844 & Não \\
\hline
\end{tabular}

Fonte: Autores.

O método apresentou 9 trechos críticos, os quais concentram 85 acidentes. Isso corresponde a 16,3\% do total da extensão analisada e cerca de $35 \%$ do total de acidentes na rodovia.

\subsection{Metodologia PARE-MT}

Para a aplicação deste método (BRASIL, 2002) os acidentes associados a cada subtrecho foram classificados quanto a sua severidade e correlacionados aos diferentes pesos da Unidade Padrão de Severidade (UPS). Foram eliminados trechos com um número de acidentes menor ou igual a 3, exceto aqueles com registro de pelo menos um óbito no período de estudo, atendendo aos procedimentos previstos do método.

Os resultados de parte dos subtrechos classificados como críticos são apresentados na Tabela 3.

Tabela 3: Segmentos críticos definidos a partir do Método PARE-MT para o ano de 2015.

\begin{tabular}{c|c|c|c|c|c|c|c}
\hline PNV $(\mathrm{km})$ & $\begin{array}{c}\text { Segmentos } \\
(\mathrm{km})\end{array}$ & UPS & VMD & $\begin{array}{c}\text { Extensão } \\
(\mathrm{km})\end{array}$ & $\begin{array}{c}\text { T } \\
\text { utilizados }\end{array}$ & Média & Criticidade \\
\hline \multirow{3}{*}{$2,5-6,0$} & $2,5-3,5$ & 17 & 29.142 & 1 & 1,60 & 5,26 & Não \\
\cline { 2 - 8 } & $3,5-4,5$ & 47 & 19.484 & 1 & 6,61 & 5,26 & Crítico \\
\cline { 2 - 8 } & $4,5-6,0$ & 33 & 19.484 & 1,5 & 3,09 & 5,26 & Não \\
\cline { 2 - 8 } & $6,0-7,4$ & 27 & 19.484 & 1,4 & 2,71 & 5,26 & Não \\
\cline { 2 - 8 } & $7,4-8,4$ & 29 & 19.484 & 1 & 4,08 & 5,26 & Não \\
\cline { 2 - 8 }
\end{tabular}

Fonte: Autores.

Correspondem a 7 o número de trechos críticos identificados por esse método. Eles compreendem 12,25\% da extensão avaliada e concentram cerca de $36 \%$ dos acidentes, o que equivale a 87 acidentes.

\subsection{Método Meneses}

$\mathrm{Na}$ identificação de locais críticos por este método (MENESES, 2001), os acidentes de cada subtrecho foram classificados de acordo com sua severidade sendo associado ao Número Equivalente de Acidentes (NEAt). Para obtenção do 
trecho crítico, realizou-se um teste estatístico em que o nível de significância adotado foi de 5\%, o mesmo utilizado no método do DNIT. Pode-se perceber que o método proposto por Meneses incorpora aspectos do método do DNIT e do PARE-MT.

Parte dos subtrechos críticos obtidos encontram-se na Tabela 4.

Tabela 4: Segmentos críticos definidos a partir do Método do Meneses para o ano de 2015.

\begin{tabular}{c|c|c|c|c|c|c|c|c|c|c}
\hline $\begin{array}{c}\text { PNV } \\
(\mathrm{km})\end{array}$ & $\begin{array}{c}\text { Segmentos } \\
(\mathrm{km})\end{array}$ & NEA & VMD & $\begin{array}{c}\text { Extensão } \\
(\mathrm{km})\end{array}$ & $\mathrm{Z}$ & Ms & IAs & Imt & Ics & Criticidade \\
\hline \multirow{2}{*}{$0-2,5$} & $0-1,5$ & 4 & 29.142 & 1,5 & 1,645 & 15,955 & 0,251 & 0,451 & 0,697 & Não \\
\cline { 2 - 11 } & $1,5-2,5$ & 8 & 29.142 & 1 & 1,645 & 10,637 & 0,736 & 0,451 & 0,743 & Não \\
\hline \multirow{3}{*}{$2,5-6,0$} & $2,5-3,5$ & 17 & 29.142 & 1 & 1,645 & 10,637 & 1,598 & 2,417 & 3,155 & Não \\
\cline { 2 - 11 } & $3,5-4,5$ & 40 & 19.484 & 1 & 1,645 & 7,112 & 5,625 & 2,417 & 3,306 & Crítico \\
\cline { 2 - 10 } & $4,5-6,0$ & 33 & 19.484 & 1,5 & 1,645 & 10,667 & 3,094 & 2,417 & 3,154 & Não \\
\hline
\end{tabular}

Fonte: Autores.

Esse método identificou o maior número de trechos críticos: 14 ao total. Esses correspondem a 23,30\% da extensão total e concentram 115 acidentes, equivalendo a $47 \%$ dos acidentes computados.

\section{Comparação dos métodos e análises dos resultados}

Em todos os métodos aplicados (DNIT, Meneses e PARE-MT) o trecho é identificado como crítico quando o índice relacionado ao número de acidentes daquele trecho for superior a uma referência pré-estabelecida. Essa está associada a uma média do número de acidentes que ocorreram na extensão total do trecho analisado. Estes métodos levam também em consideração a neutralização da influência do volume veicular.

Segue a Tabela 5, o qual apresenta características dos métodos utilizados quanto aos parâmetros, vantagens e limitações.

Tabela 5: Características dos Métodos Numéricos e Estatísticos.

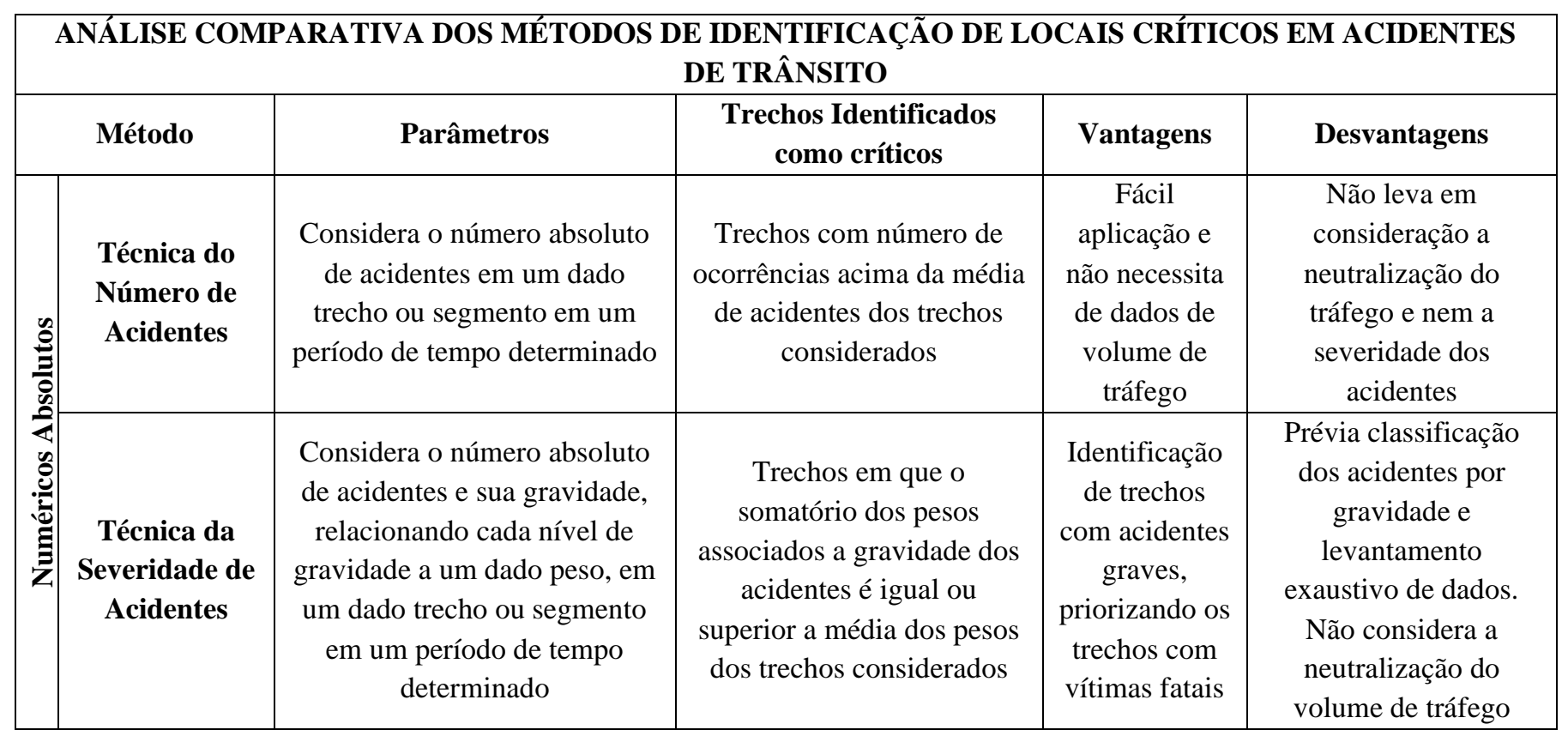




\begin{tabular}{|c|c|c|c|c|c|}
\hline 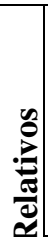 & $\begin{array}{c}\text { Técnica da } \\
\text { Taxa de } \\
\text { Acidente }\end{array}$ & $\begin{array}{l}\text { Considera a quantidade de } \\
\text { acidentes de trânsito e o } \\
\text { volume de tráfego em cada } \\
\text { local }\end{array}$ & $\begin{array}{l}\text { Trechos com taxa de } \\
\text { ocorrências acima da taxa } \\
\text { média de acidentes dos } \\
\text { trechos considerados }\end{array}$ & $\begin{array}{c}\text { A } \\
\text { neutralização } \\
\text { da influência } \\
\text { do volume de } \\
\text { tráfego } \\
\end{array}$ & $\begin{array}{l}\text { Não leva em } \\
\text { consideração a } \\
\text { severidade dos } \\
\text { acidentes }\end{array}$ \\
\hline |ֶ, & $\begin{array}{c}\text { Técnica da } \\
\text { Taxa de } \\
\text { Severidade } \\
\text { dos Acidentes }\end{array}$ & $\begin{array}{l}\text { Considera a quantidade de } \\
\text { acidentes de trânsito, a } \\
\text { gravidade e o volume de } \\
\text { tráfego em cada local }\end{array}$ & $\begin{array}{l}\text { Trechos em que o taxa dos } \\
\text { pesos associados a } \\
\text { gravidade dos acidentes é } \\
\text { igual ou superior a taxa } \\
\text { média dos pesos dos } \\
\text { trechos considerados }\end{array}$ & $\begin{array}{c}\text { A } \\
\text { neutralização } \\
\text { da influência } \\
\text { do volume de } \\
\text { tráfego }\end{array}$ & $\begin{array}{c}\text { Levantamento } \\
\text { exaustivo de dados e } \\
\text { prioriza locais com } \\
\text { menores volumes de } \\
\text { tráfego }\end{array}$ \\
\hline & $\begin{array}{c}\text { Método } \\
\text { Estatístico }\end{array}$ & $\begin{array}{l}\text { Considera a quantidade de } \\
\text { acidentes, volume de tráfego e } \\
\text { modelos matemáticos } \\
\text { probabilísticos }\end{array}$ & $\begin{array}{c}\text { Trechos em que o risco de } \\
\text { acidente é superior ao } \\
\text { estimado pelo modelo } \\
\text { matemático }\end{array}$ & $\begin{array}{l}\text { Prevê o risco } \\
\text { de acontecer } \\
\text { um acidente } \\
\text { antes da } \\
\text { ocorrência do } \\
\text { mesmo }\end{array}$ & $\begin{array}{c}\text { Exige levantamentos e } \\
\text { aplicação de modelos } \\
\text { e não leva em } \\
\text { consideração a } \\
\text { severidade }\end{array}$ \\
\hline
\end{tabular}

Fonte: Adaptado Brandão (2007).

Foram analisados ao todo 54 trechos nos métodos estatísticos do DNIT e Meneses, enquanto o método numérico do PARE-MT levou em consideração somente 21 trechos. Fato explicado devido ao método ter como procedimento a exclusão dos locais que não possuem óbito e com número de acidentes menor ou igual a três.

Como apresentado anteriormente, no método do DNIT foram identificados 9 trechos críticos, no de Meneses foram contabilizados 14 trechos e o método do PARE-MT identificou apenas 7. Este último obteve um valor elevado de média de referência, já que alguns trechos foram desconsiderados, e, por conseguinte resultou em uma menor quantidade de locais críticos. O método de Meneses apresentou um maior número de trechos considerados críticos que os demais métodos. Isto deveu-se ao fato deste utilizar o mesmo procedimento de cálculo do DNIT, acrescentando porém, a severidade dos acidentes em sua análise.

Dos subtrechos críticos obtidos, 6 deles são comuns a todos os métodos e estão presentes na Tabela 6 a seguir. Estes trechos correspondem a $11 \%$ do total de trechos definidos na rodovia BR-020 inserida no Distrito Federal, e concentram cerca de $31 \%$ dos acidentes ocorridos no período de análise. 
Tabela 6: Lista dos segmentos e suas criticidades.

\begin{tabular}{|c|c|c|c|c|c|c|c|c|c|}
\hline PNV (km) & $\begin{array}{c}\text { Segmentos } \\
(\mathbf{k m})\end{array}$ & Acidentes & UPS & NEA & VMD & $\begin{array}{c}\text { Extensão } \\
(\mathbf{k m})\end{array}$ & DNIT & $\begin{array}{c}\text { PARE- } \\
\text { MT }\end{array}$ & Meneses \\
\hline \multirow{2}{*}{$0-2,5$} & $0-1,5$ & 1 & - & 4 & 29142 & 1,5 & Não & - & Não \\
\hline & $1,5-2,5$ & 2 & - & 8 & 29142 & 1 & Não & - & Não \\
\hline \multirow{3}{*}{$2,5-6,0$} & $2,5-3,5$ & 5 & 17 & 17 & 29142 & 1 & Não & Não & Não \\
\hline & $3,5-4,5$ & 11 & 47 & 40 & 19484 & 1 & Crítico & Crítico & Crítico \\
\hline & $4,5-6,0$ & 9 & 33 & 33 & 19484 & 1,5 & Não & Não & Não \\
\hline \multirow{2}{*}{$6,0-8,4$} & $6,0-7,4$ & 10 & 27 & 27 & 19484 & 1,4 & Não & Não & Não \\
\hline & $7,4-8,4$ & 7 & 29 & 29 & 19484 & 1 & Não & Não & Não \\
\hline \multirow{10}{*}{$8,4-18,8$} & $8,4-9,8$ & 15 & 49 & 49 & 19484 & 1,4 & Não & Não & Não \\
\hline & $9,8-10,8$ & 8 & 20 & 20 & 19484 & 1 & Não & Não & Não \\
\hline & $10,8-11,8$ & 12 & 47 & 47 & 19484 & 1 & Não & Crítico & Crítico \\
\hline & $11,8-12,8$ & 6 & 23 & 23 & 20321 & 1 & Não & Não & Não \\
\hline & $12,8-13,8$ & 6 & 33 & 24 & 20321 & 1 & Não & Não & Não \\
\hline & $13,8-14,8$ & 6 & 18 & 18 & 20321 & 1 & Não & Não & Não \\
\hline & $14,8-15,8$ & 7 & 13 & 13 & 20321 & 1 & Não & Não & Não \\
\hline & $15,8-16,8$ & 15 & 42 & 42 & 20321 & 1 & Crítico & Crítico & Crítico \\
\hline & $16,8-17,8$ & 18 & 54 & 45 & 20321 & 1 & Crítico & Crítico & Crítico \\
\hline & $17,8-18,8$ & 19 & 61 & 52 & 20321 & 1 & Crítico & Crítico & Crítico \\
\hline \multirow{3}{*}{$18,8-22,6$} & $18,8-20,6$ & 14 & 32 & 32 & 19962 & 1,8 & Não & Não & Não \\
\hline & $20,6-21,6$ & 7 & 25 & 25 & 19962 & 1 & Não & Não & Não \\
\hline & $21,6-22,6$ & 11 & 35 & 35 & 19962 & 1 & Não & Não & Crítico \\
\hline \multirow{3}{*}{$22,6-25,6$} & $22,6-23,6$ & 2 & - & 8 & 19962 & 1 & Não & - & Não \\
\hline & $23,6-24,6$ & 1 & - & 4 & 19962 & 1 & Não & - & Não \\
\hline & $24,6-25,6$ & 2 & - & 5 & 19962 & 1 & Não & - & Não \\
\hline \multirow{8}{*}{$25,6-33,6$} & $25,6-26,6$ & 0 & - & 0 & 19962 & 1 & Não & - & Não \\
\hline & $26,6-27,6$ & 0 & - & 0 & 19962 & 1 & Não & - & Não \\
\hline & $27,6-28,6$ & 1 & - & 1 & 19962 & 1 & Não & - & Não \\
\hline & $28,6-29,6$ & 2 & - & 8 & 19962 & 1 & Não & - & Crítico \\
\hline & $29,6-30,6$ & 3 & - & 9 & 19962 & 1 & Crítico & - & Crítico \\
\hline & $30,6-31,6$ & 0 & - & 0 & 19962 & 1 & Não & - & Não \\
\hline & $31,6-32,6$ & 0 & - & 0 & 19962 & 1 & Não & - & Não \\
\hline & $32,6-33,6$ & 2 & - & 8 & 19962 & 1 & Não & - & Crítico \\
\hline $33,6-35,6$ & $33,6-35,6$ & 0 & - & 0 & 5838 & 1 & Não & - & Não \\
\hline $35,6-36,4$ & $35,6-36,4$ & 3 & - & 6 & 5838 & 0,8 & Não & - & Não \\
\hline \multirow{3}{*}{$36,4-41,6$} & $36,4-37,6$ & 0 & - & 0 & 5838 & 1,2 & Não & - & Não \\
\hline & $37,6-38,6$ & 1 & - & 4 & 5838 & 1 & Não & - & Não \\
\hline & $38,6-39,6$ & 0 & - & 0 & 5838 & 1 & Não & - & Não \\
\hline
\end{tabular}




\begin{tabular}{|c|c|c|c|c|c|c|c|c|c|}
\hline & $39,6-40,6$ & 2 & - & 10 & 5838 & 1 & Crítico & - & Crítico \\
\hline & $40,6-41,6$ & 0 & - & 0 & 5838 & 1 & Não & - & Não \\
\hline \multirow{7}{*}{$41,6-48,8$} & $41,6-42,8$ & 1 & - & 1 & 5838 & 1,2 & Não & - & Não \\
\hline & $42,8-43,8$ & 1 & - & 1 & 5838 & 1 & Não & - & Não \\
\hline & $43,8-44,8$ & 3 & - & 6 & 5838 & 1 & Não & - & Não \\
\hline & $44,8-45,8$ & 2 & - & 5 & 5838 & 1 & Não & - & Não \\
\hline & $45,8-46,8$ & 3 & - & 9 & 4089 & 1 & Não & - & Crítico \\
\hline & $46,8-47,8$ & 4 & 19 & 10 & 4089 & 1 & Crítico & Crítico & Crítico \\
\hline & $47,8-48,8$ & 2 & - & 5 & 4089 & 1 & Não & - & Não \\
\hline \multirow{3}{*}{$48,8-52,1$} & $48,8-50,1$ & 5 & 14 & 14 & 5788 & 1,3 & Crítico & Não & Crítico \\
\hline & $50,1-51,1$ & 0 & - & 0 & 5788 & 1 & Não & - & Não \\
\hline & $51,1-52,1$ & 2 & - & 5 & 5788 & 1 & Não & - & Não \\
\hline \multirow{5}{*}{$52,1-57,1$} & $52,1-53,1$ & 1 & - & 1 & 5788 & 1 & Não & - & Não \\
\hline & $53,1-54,1$ & 1 & - & 4 & 5788 & 1 & Não & - & Não \\
\hline & $54,1-55,1$ & 1 & - & 4 & 5788 & 1 & Não & - & Não \\
\hline & $55,1-56,1$ & 3 & - & 6 & 5788 & 1 & Não & - & Não \\
\hline & $56,1-57,1$ & 8 & 35 & 26 & 5788 & 1 & Crítico & Crítico & Crítico \\
\hline
\end{tabular}

Fonte: Autores.

Ao se observar os resultados obtidos, nota-se a influência que a extensão do subtrecho, o volume de tráfego e a consideração da severidade nos métodos têm na determinação dos trechos críticos.

Comparando-se os trechos do $\mathrm{Km} \mathrm{8,4} \mathrm{ao} \mathrm{9,8} \mathrm{e} \mathrm{do} \mathrm{Km}$ 15,8 ao 16,8 é possível verificar a interferência da extensão no resultado. Ambos possuem o mesmo número de acidentes, entretanto, o Km 15,8 ao 16,8 é considerado crítico e o Km 8,4 ao 9,8 não, devido à diferença de extensão dos seus trechos de 400 metros.

Em relação ao volume de tráfego, ao se comparar os trechos do $\mathrm{Km} \mathrm{9,8}$ ao 10,8 e do $\mathrm{Km} 56,1$ ao 57,1 percebe- se a influência do volume médio diário, pois apresentam o mesmo número de acidentes, contudo um é considerado crítico e o outro não. Enquanto este, considerado crítico, possui um volume médio diário de 5788 veículos, aquele tem um volume de 19484 veículos.

A classificação dos acidentes quanto à severidade é relevante para identificação de locais que apresentam um baixo padrão de segurança viária, e importante também para hierarquizar estes locais segundo o grau de risco representado. Isto pode ser observado, por exemplo, no trecho do $\mathrm{Km} \mathrm{10,8}$ ao 11,8, o qual apresentou 1 acidente sem vítima, 10 com vítimas e 1 atropelamento, sendo considerado crítico nos métodos de Meneses e PARE-MT. O método do DNIT, porém, classificou este trecho como não crítico, já que não prioriza os trechos que contém acidentes com vítimas, atropelamentos e vítimas fatais, considerando apenas o número absoluto de acidentes em cada trecho.

Dessa forma, vê-se a necessidade de análises complementares para verificar se de fato um trecho classificado como não crítico pode ser desconsiderado de forma a não ter seus aspectos referentes a segurança analisados. 


\section{Medidas Mitigadoras}

A metodologia PARE-MT apresenta um quadro em que associa o tipo de acidente às suas prováveis causas com suas respectivas medidas mitigadoras. Assim, utilizando dessa metodologia, serão analisados segmentos críticos comuns propondo as correções necessárias de forma a minimizar os acidentes.

Foi observada, no trecho do $\mathrm{km} \mathrm{3,5}$ ao 4,5, a predominância de acidentes do tipo colisão traseira e capotamento. Suas causas prováveis compreendem o excesso de velocidade induzidos pelas características da via, como alta declividade e largura excessiva, e acesso ao trecho por meio uma via marginal a poucos metros da curva, que além de ocasionar colisões traseiras, aumenta o risco de mudanças bruscas no trecho. As possíveis medidas corretivas englobam adequação do layout do trecho dentro dos padrões técnicos da geometria horizontal, buscando soluções voltadas à redução das velocidades, tais como: redimensionamento de curvas horizontais, alteração de traçado nas aproximações da interseção forçando a redução da velocidade, implantação de passeios, reduzindo o excesso de área de circulação. Também deve ser feita a realocação do controle de velocidade, que atualmente encontra-se após a curva.

O trecho do km 15,8 ao 18,8 apresenta um grande número de colisões traseiras, capotamento e saída de pista. As causas mais prováveis destes acidentes decorrem da travessia irregular de pedestres, ocasionando freada bruscas, visibilidade precária devido às curvas verticais côncavas e velocidade excessiva. As medidas mitigadoras mais indicadas são a regulamentação das travessias de pedestres em locais de alta movimentação, implantação de uma sinalização viária mais eficiente e adoção de barreiras eletrônicas para maior controle de velocidade.

No trecho do $\mathrm{km} \mathrm{46,8}$ ao 47,8, há predominância de saída de pista, devido principalmente ao layout do trecho associada a altas velocidades e aquaplanagem. As medidas corretivas devem promover uma mudança no layout, assim como já visto no trecho do $\mathrm{km} \mathrm{3,5}$ ao 4,5 e propor uma drenagem mais adequada da pista.

Por fim, o trecho do $\mathrm{km} \mathrm{56,1} \mathrm{ao} \mathrm{57,1,} \mathrm{a} \mathrm{colisão} \mathrm{traseira} \mathrm{e} \mathrm{capotamento} \mathrm{são} \mathrm{os} \mathrm{acidentes} \mathrm{mais} \mathrm{frequentes,} \mathrm{sendo}$ causados principalmente pela alta velocidade do trecho, associada a uma curva horizontal acentuada e falta de sinalização horizontal e vertical adequada. As ações corretivas indicadas são a mudança na localização da barreira eletrônica e melhoria na sinalização.

Após a implementação das medidas mitigadoras é essencial que se diagnostique o efeito do tratamento, através de seu monitoramento, para que seja verificada a efetividade das modificações adotadas nos trechos.

\section{Conclusões}

Em consequência da aplicação dos métodos apresentados anteriormente, foram identificados os segmentos críticos da rodovia selecionada. A partir dos resultados, realizou-se uma análise comparativa dos métodos e verificou-se que informações como volume de tráfego, extensão do segmento e a severidade do acidente influenciam na identificação de um trecho como crítico ou não crítico.

Constatou-se ainda que o método do DNIT classificou menos pontos críticos que o método de Meneses (2001), o que ocorreu pela metodologia não diferenciar os acidentes quanto a severidade, ou seja, todos os acidentes apresentam o mesmo peso. O método PARE-MT, por sua vez, examinou menos da metade dos trechos analisados pelos demais métodos aplicados. Essa diferença decorre da exclusão dos segmentos que apresentaram três acidentes ou menos, sem óbito. Dessa forma, ressaltase a necessidade de um estudo para verificar os reais impactos da exclusão desses trechos. Dentre os métodos aplicados nesse estudo, considera-se que o mais completo para identificar os trechos críticos foi o método desenvolvido por Meneses (2001), pois contempla a severidade e abrange a extensão total da rodovia.

A partir dos trechos críticos identificados, realizou-se visitas in loco e utilizou-se ferramenta do software Google Earth para observar as características dos locais concentradores de acidentes. Deficiência na sinalização horizontal e vertical, 
defeitos geométricos da via e falta de mecanismos de controle da velocidade, estão entre os fatores que contribuem para a significativa quantidade de acidentes nesses trechos.

Percebe-se com essa pesquisa, a importância da identificação dos trechos críticos na melhoria da segurança viária e apesar desta promover uma série de benefícios como maior qualidade de vida e economia ao estado, é notável a falta desse tipo de análise nas rodovias nacionais.

Por fim, como proposta de trabalhos futuros, sugere-se o aprofundamento dos estudos relacionados às medidas mitigadoras e sua eficácia, como também o desenvolvimento de uma metodologia que atualize e corrija as deficiências encontradas nas metodologias adotadas.

\section{Referências}

ABNT NBR-12.898, de 30 de novembro de 1993. Relatório de acidente de trânsito (RAT) - Procedimento Rio de Janeiro: Associação Brasileira de Normas Técnicas.

Andreuccetti, G, Carvalho, H. B., Cherpite, C, J., YuYe, Ponce, J, C., Kahn, T., \& Leyton, V. (2011) Reducing the legal blood alcohol concentration limit for driving in developing countries: a time for change? Results and implications derived from a time-series analysis (2001-10) conducted in Brazil. Addiction, $106,2124-2131$

Brasil (2002). MT - Ministério de Transportes. CEFTRU- Centro de Formação de Recursos Humanos em Transportes - UnB - Universidade de Brasília. Procedimentos para o tratamento de locais críticos de acidentes de trânsito. TDA desenho e arte, 2002. 75p.

Brasil (2006). DNIT - Departamento Nacional de Infraestrutura de Transportes, UFSC - Universidade Federal de Santa Catarina, Laboratório de Transportes e Logística, Núcleo de Estudos sobre Acidentes de Tráfego em Rodovias. Metodologia para Tratamento de Acidentes de Tráfego em Rodovias.

Brasil (2009). DNIT - Departamento Nacional de Infraestrutura de Transporte, UFSC - Universidade Federal de Santa Catarina. Elaboração de Ações Preventivas e Corretivas de Segurança Rodoviária, por meio de Identificação e Mapeamento dos Segmentos Críticos da Malha Viária do DNIT.

Brasil (2010). Plano nacional de viação - PNV. http://www.dnit.gov.br/sistema-nacional-de-viacao/sistema-nacional-de-viacao

Brasil (2015). MT - Ministério dos Transportes, Programa de Redução de Acidentes no Trânsito. Brasília. http://www.transportes.gov.br/.

Brandão, L. C. (2007). Discussão sobre Métodos para Identificação de Locais Críticos em Acidentes de Trânsito no Brasil. Campinas.

CNT, Painel de Acidentes rodoviários, https://www.cnt.org.br/painel-acidente

CNT (2015). Confederação Nacional do Transporte. Pesquisa CNT de rodovias 2015: relatório gerencial. CNT

CNT (2019). Confederação Nacional do Transporte. Pesquisa CNT de rodovias 2019: relatório gerencial. CNT

CNT (2021) Confederação Nacional do Transporte. Conjuntura do Transporte: Investimentos.:CNT

Gold, P. A. (1998). Segurança de trânsito - Aplicações de engenharia para reduzir acidentes. Banco Interamericano de Desenvolvimento.

Henrique, M. C. (2002). Anos potenciais de vida perdidos: a herança dos acidentes de trânsito para as futuras gerações - uma abordagem interdisciplinar. 184p. Tese (Doutorado em Ciências Humanas) - Curso de Pós-graduação Interdisciplinar em Ciências Humanas, Universidade Federal de Santa Catarina, Florianópolis.

IPEA (2020) - Impactos de Pesquisa Econômica Aplicada. Acidentes de Trânsito nas Rodovias Federais Brasileiras: Caracterização, Tendências e Custos para a Sociedade.

Luz, V. P. (1994) Trânsito e veículos: ações cíveis, ações criminais, prática e jurisprudência. (3a ed.), Sagra - DC Luzzatto, 212p.

Meneses, F. A. B. (2001). Análise e tratamento de trechos rodoviários críticos em ambientes de grandes centros urbanos. 251p. Dissertação (Mestrado em Ciências em Engenharia de Transporte) - Curso de Pós-graduação em Engenharia de Transportes, Universidade Federal do Rio de Janeiro, COPPE, Rio de Janeiro.

Pereira A. S, Shitsuka, D. M., Parreira, F. J. \& Shitsuka, R. (2018). Metodologia da pesquisa científica. UFSM.

PRF (2016) Site a Polícia Rodoviária Federal. Dados Abertos de Acidentes. https://www.prf.gov.br/portal/dados-abertos/

Rozestraten, R. J. A. (1998). Psicologia do trânsito: conceitos e processos básicos. EPU - Editora da Universidade de São Paulo.

Schwab, K. (2019). The Global Competitibenes Report. World Economic Forum.

WHO (2018) Global status report on road safety 2018. Switzerland, 424p 